\title{
Research on Energy Conservation of Shopping Malls in China
}

\author{
Weihan $\mathrm{Li}^{1 \text {,* }}$ \\ ${ }^{1}$ Southwest Jiaotong University Leeds Joint School, 611756, Chengdu, Sichuan, China
}

\begin{abstract}
Energy is an indispensable part of human life. People's life is inextricably linked with energy, and energy will also have a significant impact on social stability. In view of the urgency of energy conservation and the huge consumption of energy in the building industry, this paper analyzes the current situation of energy conservation and technical improvement of shopping mall buildings. First of all, this paper analyzes the current situation of energy-saving in shopping malls in China and figures out the existing problems of energy-saving in shopping malls at the current stage. Secondly, this paper offers some potential measures to improve the efficiency of energy-saving shopping malls from the site selection, HVAC, lighting energy saving these three aspects.
\end{abstract}

\section{Introduction}

Environmental pollution, energy shortage and population expansion have become the three major problems facing the world today, and they are also the key topics that human beings must explore normal ways to conduct research to achieve sustainable development. Although China occupies third place in the world's total energy, the per capita amount of energy in China is less than half of the world's average level. Energy shortage has become a key factor affecting the sustainable development of society and the economy in the future. Since the reform and opening up in China, the shopping mall has been a symbol of the city's economic prosperity, rapid development and thriving. However, most of these large public buildings are high energy consumption construction. Large public buildings in our country according to area accounts for only one percent of the total existing buildings across the country, but their amount of building energy consumption accounts for about four percent of the total energy consumption of buildings in the nation traffic, which is much higher than other buildings. By 2018, the area of public buildings has reached $40 \%$, and those with central air conditioning account for $80 \%$ of public buildings. The energy consumption of central air conditioning usually accounts for $40 \%$ to $60 \%$ of the building's electric power, and there is still an upward trend. It is the main energy consumption equipment in modern public buildings, which brings a heavy burden to building energy saving buildings[1]. In addition, the energy operation cost of lighting system occupies a large part of the total energy consumption of a building, and it will change according to the function of the building[2]. The energy cost of lighting is high because of the high population density and long opening hours. After comparing the average value of the annual consumption data of hotel, shopping mall and office building per unit area, the annual power consumption per unit area of shopping mall building is close to $150 \mathrm{kWh} / \mathrm{m} 2$, , almost twice as many as hotels and office buildings. Therefore, the energy saving potential of shopping malls in lighting electricity is huge. Apart from these two internal factors, the location of shopping malls can also greatly affect the energy-saving situation of shopping malls.

\section{Present situation of energy consumption of domestic shopping malls}

Since the 1880s, China has gradually started building energy-saving buildings, compared with western developed countries, China's building energy-saving development is relatively late.

As is shown in Figure 1 and 2, in 2017, China's total building energy consumption was 947 million tons of standard coal, accounting for $21.10 \%$ of the country's total energy consumption. Public buildings consumed 363 million tons of standard coal, accounting for $38.37 \%$ of the total building energy consumption. The energy consumption of urban residential buildings was 361 million tons of standard coal, accounting for 38.09\%; The energy consumption of rural residential buildings was 223 million tons of standard coal, accounting for $23.55 \%$ [3]. Energy consumption in public buildings accounts for a large part. As a kind of public buildings, shopping malls operate for more than 12 hours a day and there are almost no holidays throughout the year. Compared with other public buildings, shopping malls have large energy consumption and huge energy-saving potential. In the energy-saving design of shopping malls in our country, the energy-saving technology used by some building units has not been verified by the system. The air-conditioning system of shopping malls has the

* Corresponding author: liweihan2001@ $163 . c 0 m$ 
problems of poor automatic adjustment ability, low energy efficiency value of the system and high energy consumption of indoor ambient temperature regulation. In addition, due to the large building area of the shopping mall, the concentrated flow of people, and the high density of various lighting equipment, the power consumption is huge. To this end, only increasing the application of the concept of energy conservation, and solving the current problems, can effectively eliminate the adverse effects of energy shortage.

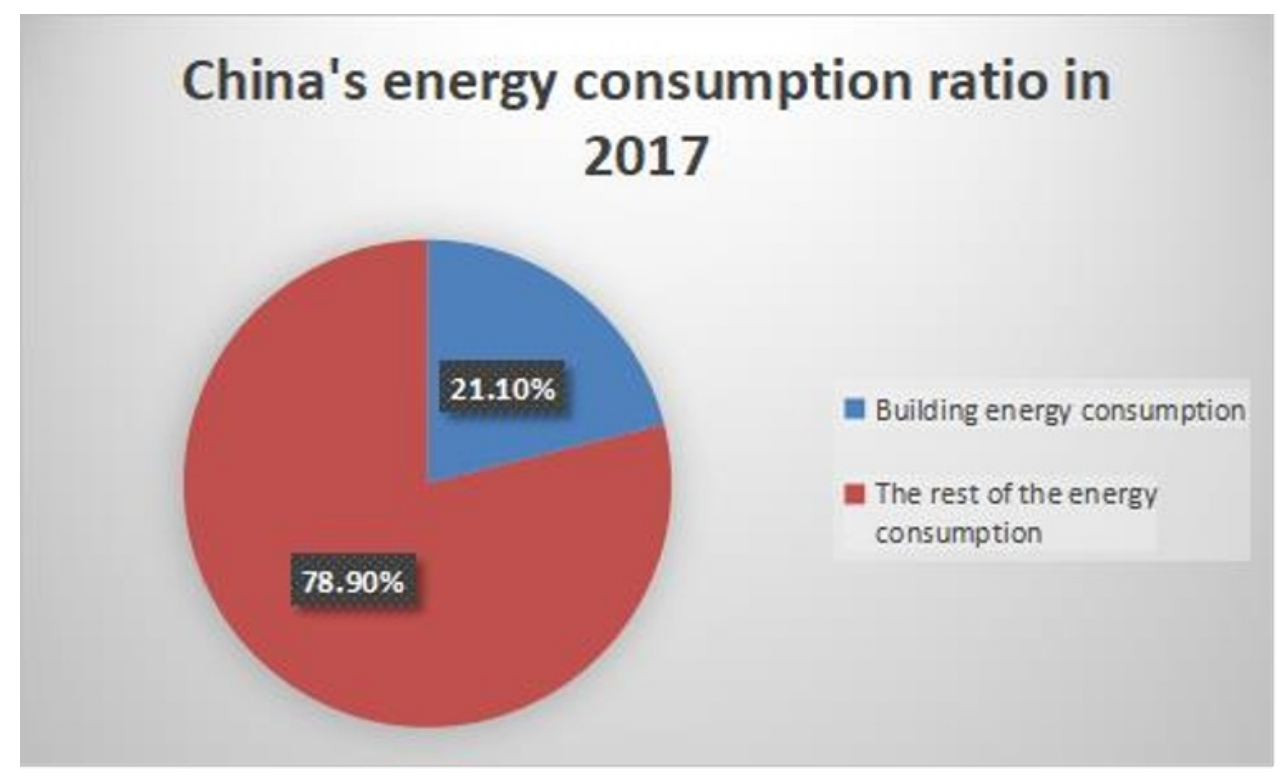

Fig1. China's energy consumption ration in 2017 (China Association of Building Energy Efficiency, 2020 )

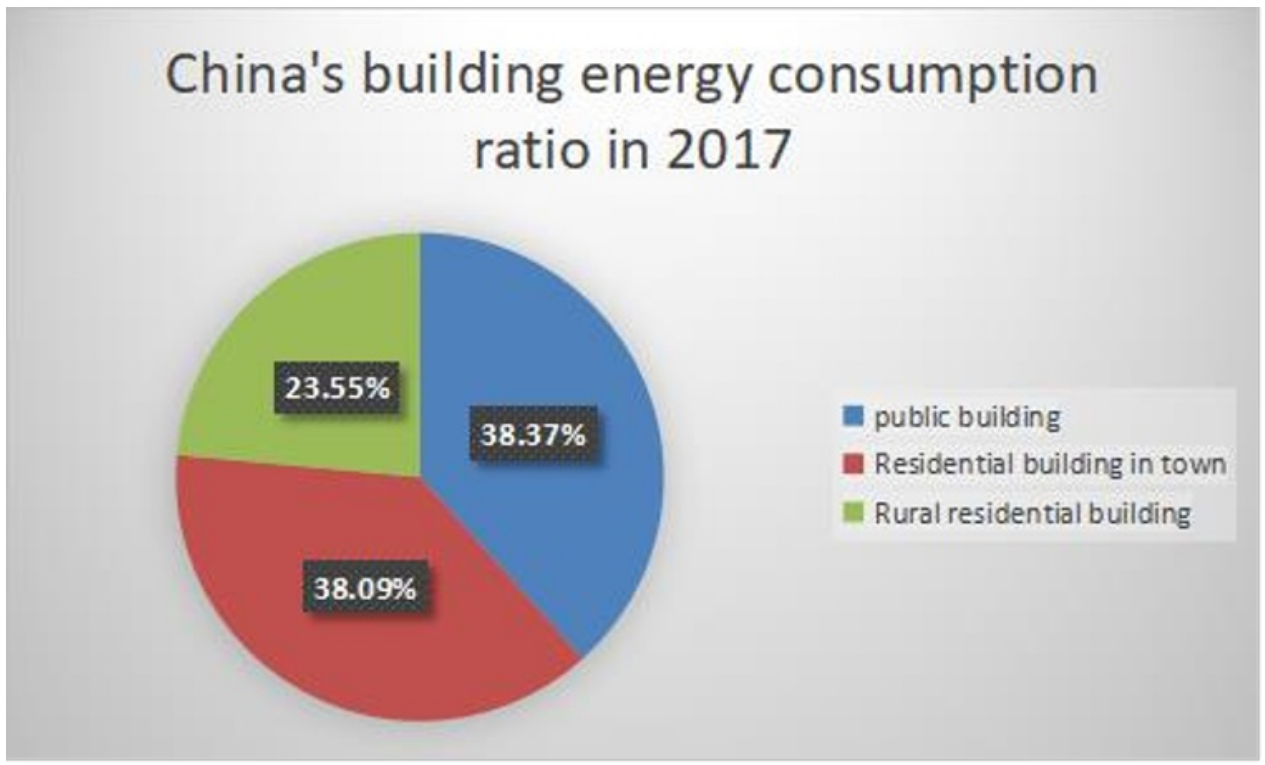

Fig2. China's building consumption ration in 2017(China Association of Building Energy Efficiency, 2020 )

\section{Energy-saving renovation design of shopping malls}

\subsection{The location principle}

A professional market research is required before the location of a shopping mall is selected. The energy-efficient design of the building needs to reflect the relationship between the building and the environment. While considering the economic benefits, shopping malls should also consider the micro-climate environment, through a reasonable site selection, to improve the overall energy-saving effect of the building 


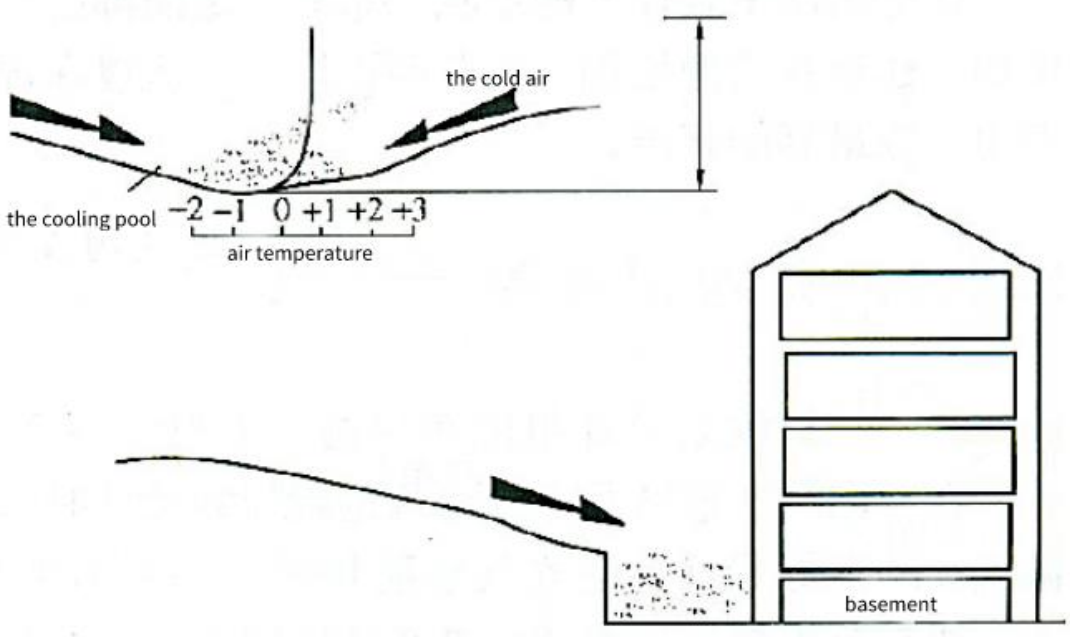

Fig3. The schematic diagram of "frost hole"

Construction should not be selected in valleys, depressions, and other concave areas. The main reason is the "frost hole" effect (as is Figure3 shown) of cold air flow on the building in the hollow in winter when the basement-level building must expend more energy to maintain the required indoor temperature.

Buildings should be sited to avoid adverse winds. The trend of cold currents in winter will affect the microclimate environment of future buildings, resulting in increased energy demand. In the design of building site selection, the closed northwest direction (the dominant direction of cold current in China) should be fully considered, and the opening direction and location of closed or semi-closed peripheral layout should be reasonably selected to achieve the purpose of wind shelter and energy saving.

The site of the building needs to avoid the accumulation of rain and snow. Improper treatment of grooves in the terrain will produce rain and snow accumulation in winter, and will take away a lot of heat in the melting process, which will reduce the ambient temperature of the building, increase the burden of insulation of the envelope structure, and is adverse to energy conservation.

\subsection{HVAC design}

The heating, ventilation and air conditioning system (HAVC) play a significant role in ensuring the building's comfort and is one of the largest sources of energy consumption in the building. It is important to develop energy-efficient HAVC systems to both protect stores from extremely high electricity costs and protect the environment from the adverse effects of greenhouse gas emissions caused by using low-energy appliances[4].

Cold storage and heat storage technology can be adopted in energy saving control of HVAC, which can effectively improve the energy-saving effect of HVAC in green buildings. The electric load of HVAC presents linear fluctuations. The load in the peak of the equipment can be transformed into the trough load, and then controlled by the way of valley filling, so as to effectively improve the utilization rate of electric energy and reduce the electric pressure of the shopping mall. Employing this valley filling method to control, can save a part of the electricity overhead, to the maximum possible savings in operating costs[5].

Cooling tower cooling is widely applied in HVAC. Cooling tower cooling can provide cooling capacity for air conditioning, which can meet the standards of energy saving and environmental protection in design theory. During the use of air conditioning in the shopping mall in winter, there will be significant differences in regional cooling temperature, and the internal humidity of the commercial complex is relatively high in winter. With the help of a cooling tower, the temperature can be effectively controlled. The advantage of a cooling tower is directly related to the temperature of backwater and water supply, and its temperature difference is the key to the function of a cooling tower. According to this principle, the application of cooling tower technology in an air conditioning system needs to scientifically set the temperature difference according to the real situation.

Evaporative cooling systems can improve the cooling and ventilation capacity of buildings with very little energy consumption. This model is very practical in shopping malls. The system uses water as the working fluid, which eliminates the use of chlorofluorocarbons and hydrochlorofluorocarbons, making it a very green system. In addition, the system is easy to install and maintain, and avoids carbon dioxide emissions[6].

\subsection{Lighting energy saving}

The energy used for lighting in shopping malls occupies a large proportion of energy. According to the research and analysis, the electric energy consumed by the lighting system accounts for about one-third [7].

At present, energy-saving and environment-friendly lighting system is advocated for buildings. Energy saving and environmental protection lighting refer to the production of scientific and reasonable lighting design, while choosing some high-quality lighting electrical products to facilitate the construction of a safe, 
environmentally friendly, comfortable, economic high-quality lighting system. In the implementation of large shopping malls' indoor lighting energy saving design, there are the following points: First, choose energy-saving and environmental protection type of electric light source; Second, choose high-quality energy-saving inductive ballast; Third, use the most reasonable lighting control system. If this part is handled reasonably, it will be possible to save more than $15 \%$ of the electric energy of the lighting system of large shopping malls[8].

Tabel 1. The intensity of lighting in different rooms

\begin{tabular}{|c|c|c|}
\hline Room & Lamp power density & Relative illumination value \\
\hline General office & 9 & 300 \\
\hline High-grade office, design studio & 15 & 500 \\
\hline The meeting room & 9 & 300 \\
\hline Business hall & 11 & 300 \\
\hline Printing room & 9 & 300 \\
\hline The archives & 7 & 200 \\
\hline
\end{tabular}

The lighting control system of the shopping mall adopts an intelligent control system, according to different functions and times to automatically adjust and control the brightness. It can effectively solve the old scene lighting control of simple, complex wiring, control points scattered, complex artificial control, no effective management and other problems. Not only can make the illumination reach the corresponding standard requirements, bright and comfortable, but also can realize the lighting system of environmental protection and energy-saving. At the same time, combined with the scientific and reasonable management mode, the maintenance and management personnel can be reduced to a large extent, thus reducing the management funds of the lighting system, improving the management level and work efficiency. The lighting density values for different rooms are shown in the table1, which should be considered when designing intelligent systems.

\section{Conclusion}

Under the background of the continuous development of the social economy, energy utilization efficiency is a hot topic in the development process of the construction industry at the present stage. In this paper, the existing problems and design methods of shopping malls are discussed, and it is found that the energy-saving design of shopping malls in China is particularly important. Shopping malls have a direct impact on the sustainable development of energy and resources in China. Therefore, the stable development of the economy can be guaranteed only by fully mastering the building energy-saving design. Shopping mall designers should always follow the geographical location and climate characteristics, focus on the HVAC design, lighting energy-saving design and other aspects of the content, and develop a reasonable design and construction scheme, in order to meet the energy saving needs of shopping malls.

I would like to thank all those who helped me during the writing of this paper. First of all, I would like to thank my professor for his help. His faithful teaching and inspiring lectures have benefited me a lot and made academic preparation for my research. In addition, I would like to thank my teacher for her time and energy in providing suggestions for the improvement of my paper Finally, I also thank my classmates for their direct and indirect help to me.

\section{References}

1. Ballarini, I, Corrado, V, Analysis of the building energy balance to investigate the effect of thermal insulation in summer conditions. Energy and Buildings 2021. 52: 168-180.

2. Laura Bellia, Francesca Fragliasso, Alessia Pedace, Lighting Control Systems: Factors Affecting Energy Savings' Evaluation, Energy Procedia, Volume 78, 2015, P. 2645-2650.

3. Research report on building energy consumption in China [J]. Building,2020(07):30-39.

4. Vahid Vakiloroaya, Bijan Samali, Ahmad Fakhar, Kambiz Pishghadam, A review of different strategies for HVAC energy saving, Energy Conversion and Management, Volume 77, 2014, P 738-754.

5. Guo Weizhao, Application of HVAC in Office Building and Shopping Mall and Energy Saving and Consumption Reduction [J]. Management and Technology of Small and Mediumsized Enterprises (next issue), 2020(08): 136-137.

6. Vahid Vakiloroaya, Bijan Samali, Ahmad Fakhar, Kambiz Pishghadam, A review of different strategies for HVAC energy saving, Energy Conversion and Management, Volume 77, 2014, P 738-754.

7. Li Cuilian. Discussion on interior lighting design of large shopping malls $[\mathrm{J}]$. Building Materials and Decoration,2018(33):79-80.

8. Li Cuilian. Discussion on interior lighting design of large shopping malls $[\mathrm{J}]$. Building Materials and Decoration,2018(33):79-80. 